http://jmscr.igmpublication.org/home/ ISSN (e)-2347-176x ISSN (p) 2455-0450 crossref DOI: https://dx.doi.org/10.18535/jmscr/v8i4.57

\title{
Association of Tuberculosis with Other Infections in Post Renal Transplant Recipients- A Retrospective Study
}

\author{
Authors \\ Karan S. Thakur ${ }^{1}$, Deepesh B Kenwar ${ }^{2}$, Ashish Sharma ${ }^{3}$,Sarabpreet Singh ${ }^{4}$ \\ *Corresponding Author \\ Purnima Patial
}

\begin{abstract}
The number of Renal Transplantations is increasing among developing nations. Tuberculosis is a big health problem in endemic countries. TB is a leading cause of morbidity and mortality in endemic countries and more common in kidney transplant patients. Renal transplant recipients are at risk for reactivation of latent Mycobacterium tuberculosis infection and primary infections. So relative risk of TB is high in organ transplantation. Other infections for example CMV, Pneumocystis carinni downgrade host immunity and may activate occult TB. Most of the cases of TB and other infections occur in the initial months of transplant surgery and during most intense period of immunosuppressant drugs. Risk of TB and associated infections depends on geographical regions also. TB is a barrier in successful long-term outcome in renal transplant. Thus this study tried to determine the association of post Renal Transplant TB with various co-infections.

Keywords: Renal Transplant, TB-Tuberculosis, CKD-Chronic Kidney disease.
\end{abstract}

\section{Introduction}

Kidney transplantation improves quality of life in patients with end stage renal disease. Infections of various kinds are among the major complications in post kidney transplant recipients. Post Renal Transplant patients require a high dose of immunosuppressant regimens to prevent graft rejections. These drugs lower immunity and body defense mechanisms. Recipients of kidney transplant are under high risk to acquire tuberculosis than the general population. Besides this, other infections for example CMV downgrade host immunity and may activate occult TB. Most of the infections occur within first year of the transplantation.

The major risk factors for development of TB are chronic liver disease, co-infections with deep mycoses, pneumocystis and nocardia and cytomegalovirus infections. Reactivation of old foci has been the most common cause of TB in these patients. The prevalence of posttransplantation $\mathrm{TB}$ is higher in developing countries like India as compared to developed countries, which is evident from various studies. Infection with Mycobacterium adds to graft dysfunction, which may be due to direct effects on graft, drug interactions and exposure to other infections. This increases both morbidity and mortality in transplant populations.

Lung involvement is the main site of presentation of TB. Other forms of involvement may be extrapulmonary and disseminated forms. The characteristic feature is fever of unknown origin. 
TB further lowers immunity in transplant recipients. Co-infections with viral, bacterial and fungal organisms are not uncommon in patients having TB post-transplant. PCP (Pneumocystiscarinni pneumonia), CMV (cytomegalovirus) and hepatitis are among the commonest associations in patients developing post Renal transplant TB.

\section{Case Study}

A retrospective non-interventional observational study, was conducted in Department of Renal Transplant Surgery, PGIMER. In this all Renal transplant patients diagnosed with TB posttransplant from $1^{\text {st }}$ January 2011 to $31^{\text {st }}$ May 2018 were taken as the sample size.

During the study period 1568 patients underwent Renal Transplant. Out of these 1568 patients 68 patients were diagnosed to have post renal transplant TB.

\section{Sources of Data}

Departmental database maintained on Microsoft Office Access supplemented by patient OPD records, indoor case files retrieved from Medical Records Department PGIMER Chandigarh and patients interviews over telephone or in person questionnaire form.

\section{Observations and Results}

In the study 1568 patients underwent Renal Transplant between 01.01.2011 to 31.05.2018. Out of these 68 patients were diagnosed with post transplant TB. In this study $4(5.9 \%)$ out 68 patients were having history of tuberculosis in past.

In the study patients having post transplant TB, had high chances of associated infections. In this study $30(44 \%)$ patients suffered with coinfections with different organisms. In 16 cases patients had viral infections. In 8 cases patients had bacterial infections. In 6 cases patients had fungal infections. In $5.9 \%$ cases patients had both bacterial and viral infection. In $2.9 \%$ cases patients had both viral and fungal infections. Among bacterial infections pneumonia, UTI etc. were the major problems. Among viral infections patients had CMV (cytomegalovirus), HBV (hepatitis B virus), HCV (hepatitis C virus), parvovirus etc. Some patients also had fungal infections associated.

\section{Details of Causative organisms}

In $\mathrm{TB}$ coinfections viral infections were in highest infections followed by bacterial \& then fungal. Percentage wise data was as followed

\begin{tabular}{|c|c|}
\hline Associated infections & Number(\%age) \\
\hline Bacterial & $\mathbf{8}(\mathbf{1 1 . 7 \%})$ \\
Cellulitis & $1(1.5 \%)$ \\
PCP (Pneumocystis carinni) & $2(2.9 \%)$ \\
Bacterial Pneumonia & $1(1.5 \%)$ \\
UTI & $1(1.5 \%)$ \\
Other bacterial & $3(4.4 \%)$ \\
\hline Viral $\quad$ CMV & $\mathbf{1 6}(\mathbf{2 3 . 5 \% )}$ \\
HCV & $2(2.9 \%)$ \\
HBV & $2(2.9 \%)$ \\
BK virus & $1(1.5 \%)$ \\
Herpes Genitalis & $1(1.5 \%)$ \\
Other viral & $1(1.5 \%)$ \\
& $9(13.2 \%)$ \\
\hline Oral candidiasis & \\
Pulmonary aspergillosis & $1(1.5 \%)$ \\
Fungal pneumonia & $1(1.5 \%)$ \\
Mycotic aneurysm & $1(1.5 \%)$ \\
Other fungal & $2(2.9 \%)$ \\
\hline
\end{tabular}

\section{Discussion}

Rates of infections remain high during the initial post transplant period because higher doses of immunosupression are given at this early post transplant time. In the study a total of 1568 patients underwent renal transplant. Sixty eight (4.34\%) patients out of them were diagnosed to have TB. Co-infections with viral, bacterial and fungal were observed in $44.1 \%$ cases in TB patients in the study. In $23.5 \%$ cases patients had viral infections. In $8 \%$ cases patients had bacterial infections. In $6 \%$ cases patients had fungal infections. In $5.9 \%$ cases patients had both bacterial and viral infection. In $2.9 \%$ cases patients had both viral and fungal infections.

The nature of various infections in transplant recipients has not been studied systematically in developing countries. Previous studies so far have shown high incidence of TB, viral, fungal and 
other bacterial infections in post transplant patients. So knowledge of association of various infections in post transplant is very necessary to decrease the morbidity and mortality in coming future.

\section{References}

1. Kalra V, Agarwal SK, Khilnani GC, Tiwari SC, Kapil A, Gupta S et al. Spectrum of tuberculosis in renal transplant recipients in tropics. International Urology and nephrology 2005;37:551-59.

2. Drobniewski FA, Ferguson J. Tuberculosis in renal transplant unit. Nephrology Dialysis Transplant 1996; 11: 768-70.

3. Canet E, Dantal J, Blancho G, Hourmant M, Coupel S. Tuberculosis following kidney transplantation. Nephrology Dialysis Transplantion 2011; 26: 3773-78.

4. Jasmer RM, Nahid P, Hopewell PC. Latent tuberculosis infection. New English Journal Med 2002; 347: 1860-66.

5. Malhotra KK, Dash SC, Dhawan IK. Tuberculosis and renal transplantationobservations from an endemic area of tuberculosis. Post Grad Med J 1986; 62: 359- 62 .

6. Subramanian A, Morris M. Mycobacterium tuberculosis Infections in Solid Organ Transplantation. American Journal of Transplantation 2013; 13: 6876. 